\title{
Comparison of SPWM, THIPWM and PDPWM Technique Based Voltage Source Inverters for Application in Renewable Energy
}

\author{
Lokesh Chaturvedi*, D. K. Yadav and Gargi Pancholi \\ Department of Electrical Engineering, RTU, Kota - 324010 \\ E-mail: chaturvedi.lucky08@gmail.com; dky_b@yahoo.com; \\ gargipancholi1992@gmail.com \\ ${ }^{*}$ Corresponding Author
}

Received 15 April 2017; Accepted 10 July 2017;

Publication 18 August 2017

\begin{abstract}
In present time, the application of the voltage source inverter (VSI) are rapidly been increasing. Different designing methods are followed for the construction of VSI. The purpose of adopting for different techniques of inverter design is to decrease the harmonic contents from the output waves of VSI. Hence the comparison of three different voltage source inverters with their different techniques is discussed in this paper for the purpose of reduction in harmonics. Total harmonic distortion (THD) analysis of all three VSI has been done. THD analysis of sine pulse width modulation (SPWM) and third harmonic injection pulse width modulation (THIPWM) is further discussed in two manners - over modulation and exact modulation. A unique type of 7 level 5 switch voltage source multi-level inverter with phase disposition pulse width modulation (PDPWM) technique is also discussed and its comparison is made with earlier two techniques. In renewable energy systems, we need to control the power generation in a very efficient manner. Hence these inverters with low THD values can be utilized in that field for reduction in losses and increase in efficiency of the renewable system. Simulation of all three techniques based VSI is done on MATLAB platform and THD is compared.
\end{abstract}

Keywords: VSI, PWM, SPWM, THIPWM, PDPWM, MLI, THD.

Journal of Green Engineering, Vol. 7, 83-98.

doi: $10.13052 /$ jge1904-4720.7125

(C) 2017 River Publishers. All rights reserved. 


\section{Introduction}

The usage of semiconductor based drives are increased in past very few years. Voltage source inverters are used for these drives as they provide power ratings from hundred to several megawatts.

As we know that, in present time whole world is concerned in generation of energy without polluting the environment without wasting any amount of energy. Hence it is compulsory now to increase the efficiency of the devices that are working in a system. In the field of electrical, the efficiency analysis of any system can be done on the basis of system THD value. If it is low then system will be more efficient or vice-versa. Yet so many researches have been made in this field, but all studies contain THD value of above $20 \%$. In this paper, an advance topologies of voltage source inverter (Multi Level Inverter) is analyzed and also been compared with two conventional topologies that may help to decrease the THD of any electrical system. An H-bridge voltage source inverter topology is considered for analysis [1]. The technique for the generation of gate pulse for h-bridge inverter are also been discussed [2].

The main function of voltage source inverter is to convert DC supply into AC supply of desired magnitude and frequency [3]. Ideally, the output waveforms of inverter should be sinusoidal but in practical, the output waveforms are not pure sinusoidal and contains different harmonics. Harmonics in any system reduces the quality of electrical supply which can cause several negative effects in the system. RMS current will get increased when harmonic will increase which cause increase in loss. Electrical system starts getting premature ageing due to harmonics. For low and moderate power applications, square and quasi-square waves are allowed but for high power application, we need sinusoidal waveforms with very low harmonic content. That's how, by using semiconductor based devices and different methods of switches pulse generation (SPWM [4], THIPWM [5] \& PDPWM [6]) the value of harmonic content can be minimized. So, taking this in mind, our aim is to design such architecture of h-bridge inverter, so that we can reduce the harmonic content from it. Due to such design, system harmonics will get reduce or we get more pure quantity sinusoidal voltage which will help to reduce the losses of the system or that's how we can manage or save the energy. The inverter system architecture with very low harmonics discussed in this paper is through PDPWM technique based voltage source multi-level inverter [7]. Novelty of this paper can be discussed in the form of THD comparison of all three simulated techniques. 


\section{Voltage Source Inverter}

Inverter are basically used for the conversion of DC to AC supply [3]. VSI drives used capacitive storage in their DC link, which stores and smooths the DC voltage of the inverter. The six-step conventional voltage source inverter design is shown below in Figure 1.

It is very important to maintain or control the output voltage of inverter. The controlling of voltage can be done as:

1. External control of inverter output voltage.

2. Internal control in inverter.

\subsection{External Control of Inverter Output Voltage}

Regulation of voltage input to $\mathrm{AC}$ load can be done by managing the firing angle of $\mathrm{AC}$ voltage controller. But, this method is rarely used now, because it creates the high harmonic content in output voltage.

\subsection{Internal Control in Inverter}

The internal control of voltage in inverter enhance the output voltage very well. Pulse width modulation is the best way to achieve such control.

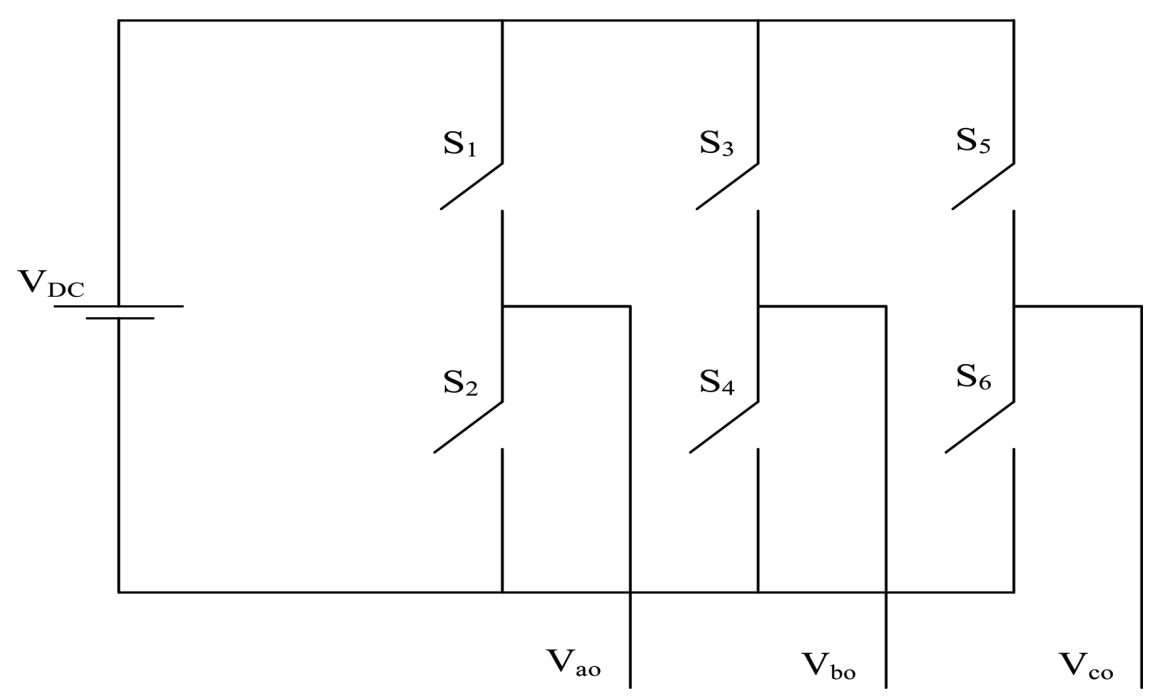

Figure 1 SPWM based voltage source inverter. 


\section{Pulse Width Modulation}

Pulse width modulation (PWM) is a strong method to control the Analog circuits with a processed digital output. PWM of power devices modulate its duty cycle to commit the control or amount of power delivered to the load. Single PWM is not suited for all type of applications. By the help of advanced technology, various methods of PWM are there for use in any application. The major aim of PWM is to maintain the output voltage and reduce the harmonic content from it. The different PWM techniques being used are:

1. Sinusoidal Pulse Width Modulation (SPWM)

2. Third Harmonic Injection Pulse Width Modulation (THIPWM)

3. Phase Disposition Pulse Width Modulation (PDPWM)

\subsection{Sinusoidal Pulse Width Modulation}

The method of sinusoidal pulse width modulation approaches the generation of sinusoidal waveform by comparing the reference to carrier waves or by filtering the pulse output waveform by varying widths of triangular waveform [4]. The basic pulse generating circuit of sine pulse width modulation scheme is shown in Figure 2. Low frequency reference sinusoidal wave form is compared with high frequency triangular waves which are called carrier waves [4]. When crossing of sine and carrier waves are happen, the switching phase gets changed at that time. In three phases, three low frequency sinusoidal reference waves $\left(\mathrm{V}_{\mathrm{a}}, \mathrm{V}_{\mathrm{b}}\right.$, and $\left.\mathrm{V}_{\mathrm{c}}\right)$ which are 120 . out of phase from each other, are compared with the triangular voltage waveform $\left(\mathrm{V}_{\mathrm{t}}\right)$, as a result we get three switching pulses for three different phases. A six-step voltage source inverter has six switches $S_{1}$ to $S_{6}$, out of these 6 switches, 2 switches will operate at a single time for one phase and are connected in series to form one leg of the inverter. Similarly, other switches will operate for other two phases. The output of each phase is connected to the center of each inverter leg as shown in Figure 1. The output of the comparator as shown in Figure 2 gives the controlling signal or pulses for the power devices connected on the three legs of the inverter. Two switches of one leg will operate in a complimentary manner it means when one is in on condition then other will be in off condition or vice-versa. The switching of outer pole voltages $\mathrm{V}_{\mathrm{ao}}, \mathrm{V}_{\mathrm{bo}}, \mathrm{V}_{\mathrm{co}}$ are done between $-\mathrm{V}_{\mathrm{dc}} / 2$ and $+\mathrm{V}_{\mathrm{dc}} / 2$ voltage levels. $\mathrm{V}_{\mathrm{dc}}$ is the total $\mathrm{DC}$ voltage.

The generation of switching gate pulse can be done by two methods, one is by over modulation method and other is by exact modulation method. For over modulation, the value of modulation index is taken 2 , whereas, for the exact 


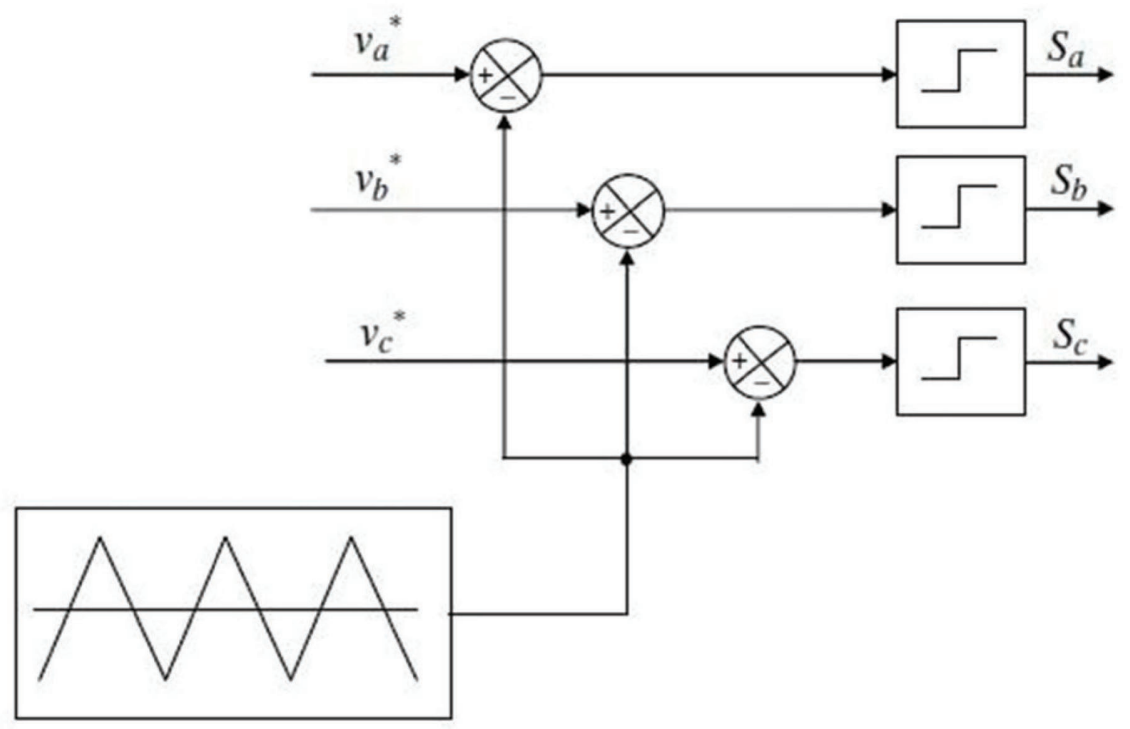

Figure 2 Controlling signal of SPWM inverter.

modulation method the value of modulation index is taken 1 . In other manner, we can say that when the peak of low frequency sinusoidal reference wave is high compared to triangular waves then system is at over modulation and when peak is at same as triangular waves then it is called exact modulation. The formula of modulation index is

$$
\text { Modulation index }(\mathrm{m})=\frac{v_{m}}{v_{c}}
$$

Positive and negative DC bus voltage will apply on each phase according to the switching states. The switches are controlled in a combination of $((\mathrm{S} 1, \mathrm{~S} 4),(\mathrm{S} 3, \mathrm{~S} 6)$, and $(\mathrm{S} 5, \mathrm{~S} 2))$ and the logic behind this is

$$
\left[\begin{array}{l}
S 1 \text { is ON when } \mathrm{V}_{a}>\mathrm{V}_{t}, \mathrm{~S} 4 \text { is } \mathrm{ON} \text { when } \mathrm{V}_{a}<V_{t} \\
S 3 \text { is ON when } \mathrm{V}_{b}>\mathrm{V}_{t}, \mathrm{~S} 6 \text { is } \mathrm{ON} \text { when } \mathrm{V}_{b}<V_{t} \\
S 5 \text { is ON when } \mathrm{V}_{c}>\mathrm{V}_{t}, \mathrm{~S} 2 \text { is ON when } \mathrm{V}_{c}<V_{t}
\end{array}\right]
$$

The width of pulse depends upon the crossing of the triangular and sinusoidal waves. The inverter output voltages can be as

$$
\left[\begin{array}{l}
V_{a}>V_{t r i} \text { then } V_{a o}=0.5 V_{d c} \\
V_{b}>V_{t r i} \text { then } V_{b o}=0.5 V_{d c} \\
V_{c}>V_{t r i} \text { then } V_{c o}=0.5 V_{d c}
\end{array}\right]
$$


And if

$$
\left[\begin{array}{l}
V_{a}<V_{t r i} \text { then } V_{a o}=-0.5 V_{d c} \\
V_{b}<V_{t r i} \text { then } V_{b o}=-0.5 V_{d c} \\
V_{c}<V_{t r i} \text { then } V_{c o}=-0.5 V_{d c}
\end{array}\right]
$$

Calculation of line to line voltage from pole voltage can be done as

$$
\left[\begin{array}{l}
V_{a b}=V_{a 0}-V_{b 0} \\
V_{b c}=V_{b 0}-V_{c 0} \\
V_{c a}=V_{c 0}-V_{a 0}
\end{array}\right]
$$

\subsection{VSI with Third Harmonic Injection Pulse Width Modulation}

Sinusoidal PWM is easy to understand and in implementation but it is not able to fully occupy the available DC bus supply voltage $[2,3]$. Due to such problem, third harmonic injection pulse width modulation (THIPWM) came in light. This method helps inverter in its performance enhancement. The sine PWM method approaches less of maximum achievable output voltage. Hence, by simply adding third harmonic signal in low frequency sinusoidal reference signal, we can achieve the amplitude increase in output voltage waveform.

Similar to sine PWM the method of overmodulation and exact modulation can also be applied in third harmonic PWM method. In THIPWM, addition of third harmonic means that, in one cycle of sinusoidal wave, three cycles of harmonic should complete. The third harmonic injection to reference signal wave is shown in Figure 3.

It is impressive that, the result of addition of the third and fundamental harmonic is less in amplitude than fundamental harmonic. On other side, the reference signal occupies two maxima at $\mathrm{t}=\pi / 3$ and $\mathrm{t}=2 \pi$ equals to 1 . The fundamental harmonic and third harmonic equations can be written as

$$
\begin{aligned}
& V_{1}=V_{1 \max } \sin . t \\
& V_{3}=V_{3 \max } \sin 3 t
\end{aligned}
$$

Hence at $\mathrm{t}=\pi / 3, V_{\text {bus }} / 2$ will be the voltage taken by the first harmonic of line to neutral output voltage. Now, the equations can be written as

$$
\frac{V_{\text {bus }}}{2}=V_{1 \max } \sin (\pi / 3)
$$

Which yields,

$$
V_{1 \max }=\frac{V_{\text {bus }}}{2}(0.86)=\frac{V_{\text {bus }}}{1.732}
$$




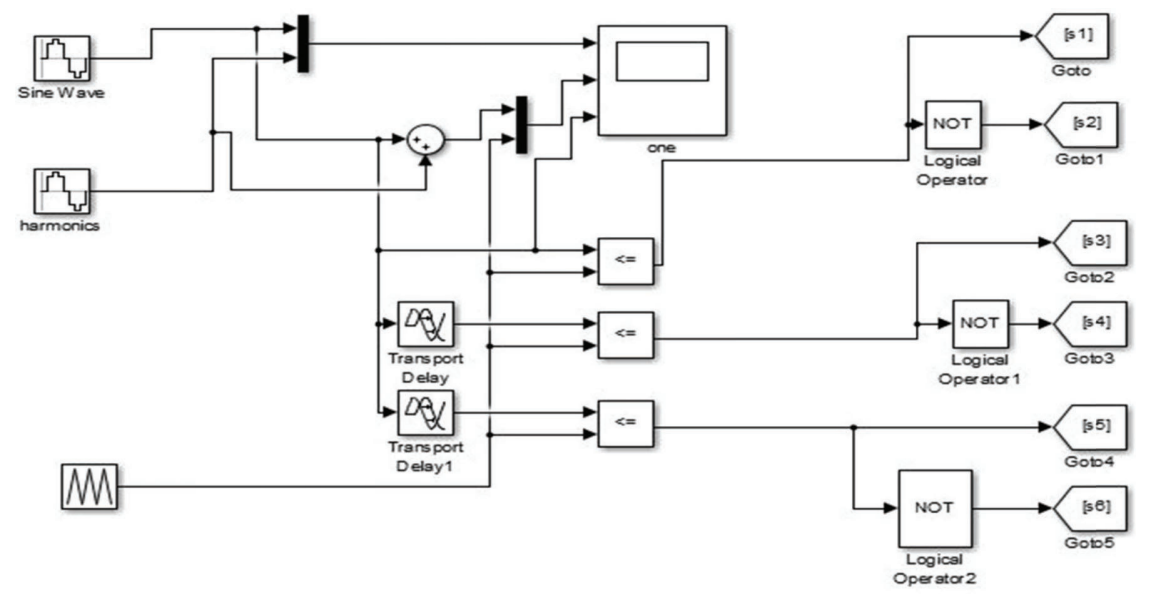

Figure 3 Third harmonic pulse generation circuit.

The output voltage waveform for each phase with third harmonic content can be written as

$$
\left[\begin{array}{c}
V_{1 \max } \sin (w t)+V_{3 \max } \operatorname{Sin}(3 w t) \\
V_{1 \max } \sin \left(w t-\frac{2 \pi}{3}\right)+V_{3 \max } \operatorname{Sin}(3 w t) \\
V_{1 \max } \sin \left(w t+\frac{2 \pi}{3}\right)+V_{3 \max } \operatorname{Sin}(3 w t)
\end{array}\right]
$$

\subsection{MLI with Phase Disposition Pulse Width Modulation}

A new unique topology of voltage source multi-level inverter containing 7 levels and 5 switch is introduced [5-7]. The proposed topology is shown in Figure 4.

It is the modified form of existing 7 level 6 switches MLI which is now reduced in 5 switches. The output voltage levels can be calculated by the formula

$$
l=2 * s-3
$$

Where, $1=$ voltage level count

$$
\mathrm{S}=\text { switches count }
$$

And,

$$
l=2 * d-1
$$

$\mathrm{d}=$ no. of DC sources 


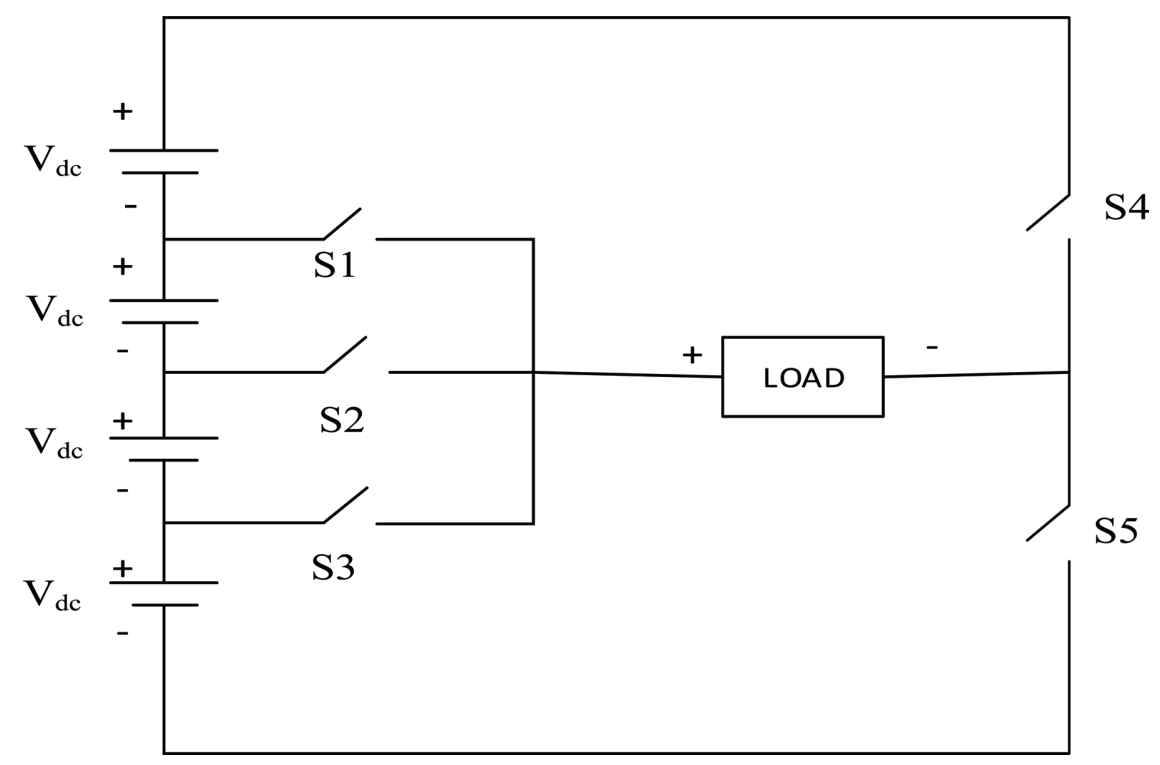

Figure 4 Level 5 switch multi-level voltage source inverter.

This topology contains 4 DC voltage sources and 5 switches which helps to produce 7 level of output voltage waveform. The switching pattern of above VSI is also done in a unique manner. When, Switches S3 and S5 will operate in same time then it gives the output voltage equal to $\mathrm{V}_{\mathrm{dc}}$. Similarly, when switches $\mathrm{S} 2$ and $\mathrm{S} 5$ will operate they will give output voltage equal to $2 \mathrm{~V}_{\mathrm{dc}}$, when switch S1 and S5 will operate they will give the output voltage equal to $3 \mathrm{~V}_{\mathrm{dc}}$. When Switch S1 and S4 will operate, they will give output voltage equals to $-\mathrm{V}_{\mathrm{dc}}$ and at the time when no switch is in operating mode the output voltage will be equal to zero.

Shift modulation technique is used here for the generation of pulses for switches. Four options are available in this modulating scheme, which are - phase disposition, phase opposition disposition, inverted phase disposition and alternative phase opposition disposition.

The comparison of sine and carrier waves is used in this method for generation of switching pulse. The output of the comparator is further provided to the appropriate switches that's how it can produce output voltage of 7 level in AC. The pulse generation circuit for voltage source multi-level inverter is shown in Figure 5. 


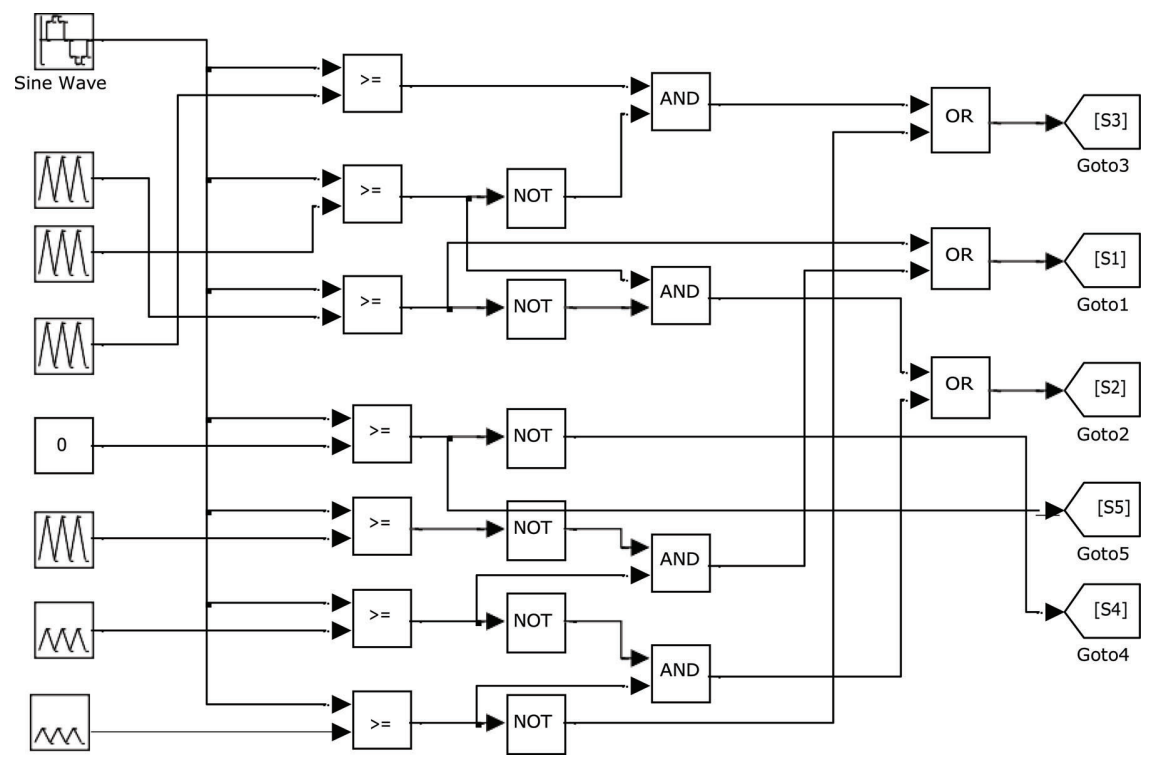

Figure 5 Pulse generation circuit for 7 Level 5 switch Multi-level VSI.

Switch $\mathrm{S} 1$ need a gate pulse to give output of $-\mathrm{V}_{\mathrm{dc}}$ and $+3 \mathrm{~V}_{\mathrm{dc}}$, switch $\mathrm{S} 2$ needs pulse to give output voltage of $+2 \mathrm{~V}_{\mathrm{dc}}$ and $-2 \mathrm{~V}_{\mathrm{dc}}$, and switch S3 requires gate pulse to produce $-3 \mathrm{~V}_{\mathrm{dc}}$ and $+3 \mathrm{~V}_{\mathrm{dc}}$. Rest switches, it means, switches S4 and S5 will operate regarding positive and negative half cycle. If we have to construct $n$ level output waveform, then will need (n-1) carrier signals. It means for above proposed inverter we need 6 carrier signals [6].

\section{Result \& THD Analysis of Proposed Inverter}

All three PWM techniques (SPWM, THIPWM and PDPWM) based voltage source inverter has been simulated on RL load in MATLAB software. The output of simulation of all three voltage source inverter is shown only for single phase. The reference sinusoidal wave frequency is taken $50 \mathrm{~Hz}$ and carrier wave frequency is taken $35 \mathrm{kHz}$. $\mathrm{V}_{\mathrm{dc}}$ is chosen 350 volts and the load is taken of $10-\mathrm{ohm}$ resistance and $10 \mathrm{mH}$ inductance in each phase. The output voltage waveform is taken across one phase and neutral of load. The output voltage waveform of all three PWM techniques based VSI is shown in Figures 6, 7 and 8. Harmonic spectrum of all three PWM techniques based VSI is shown in Figures 9, 10 and 11 [8]. 


\subsection{Output Waveforms}

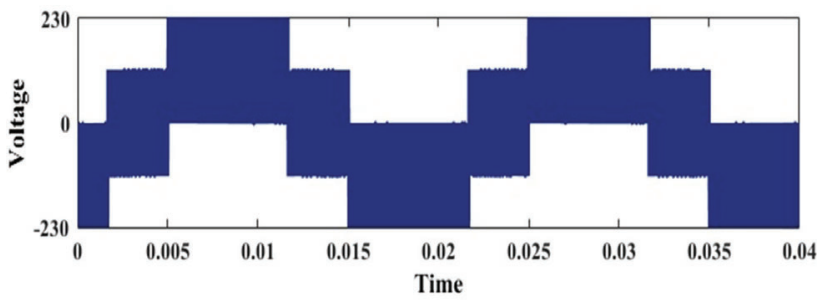

(a)

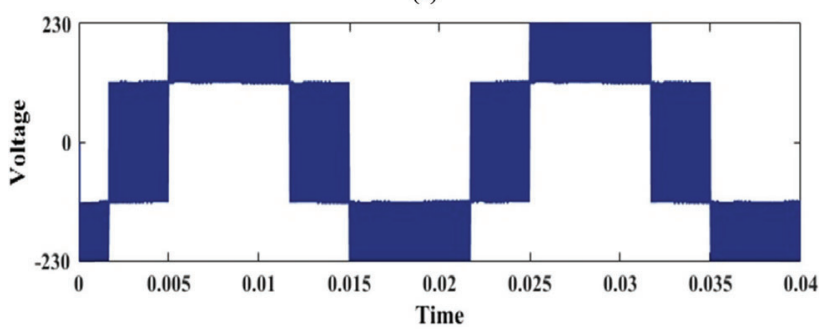

(b)

Figure 6 (a) Line to neutral voltage for SPWM with modulation index 1, (b) Line to neutral voltage for SPWM with modulation index 2.

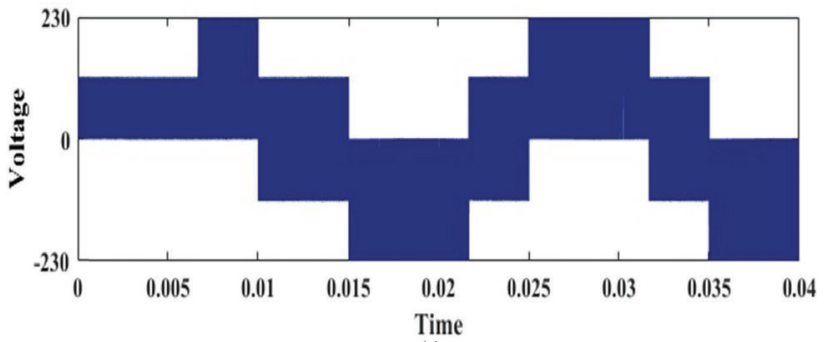

(a)

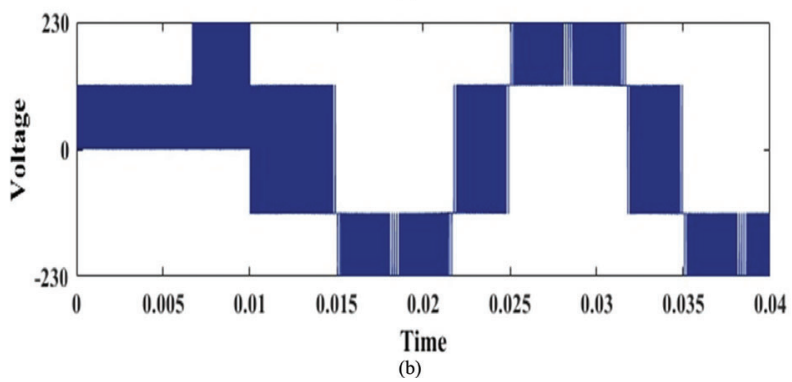

Figure 7 (a) Line to neutral voltage for THIPWM with modulation index 1, (b) Line to neutral voltage for THIPWM With modulation index 2. 


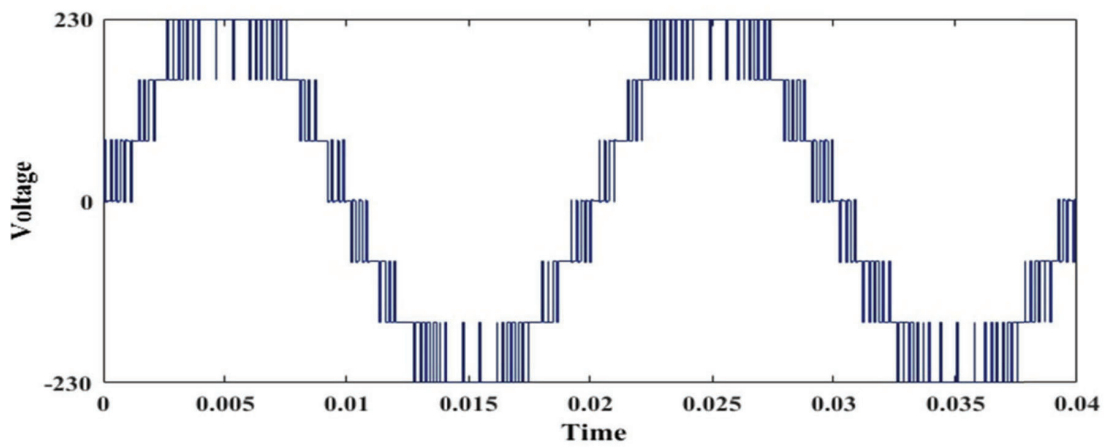

(a)

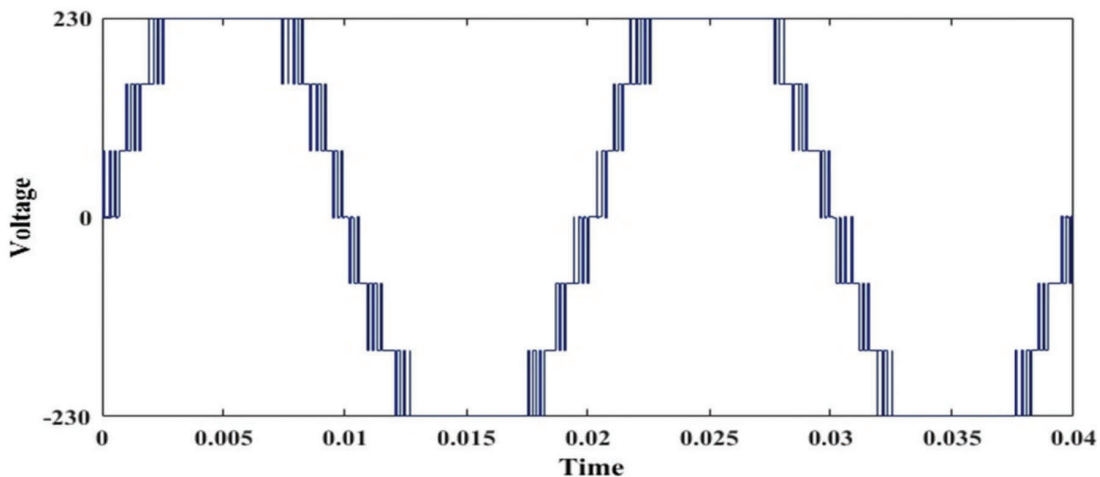

(b)

Figure 8 (a) Line to neutral voltage for PDPWM with exact modulation, (b) Line to neutral voltage for PDPWM with over modulation.

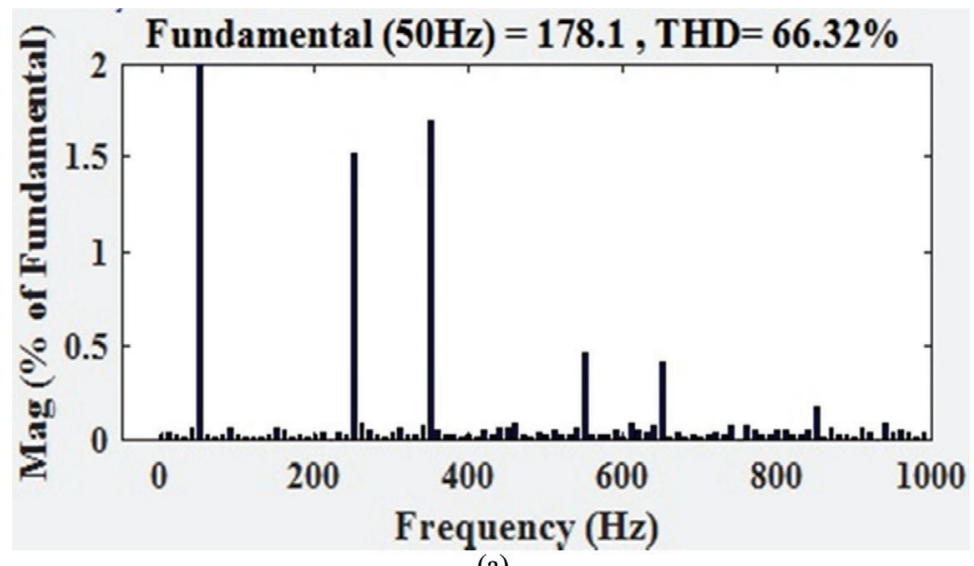

(a) 


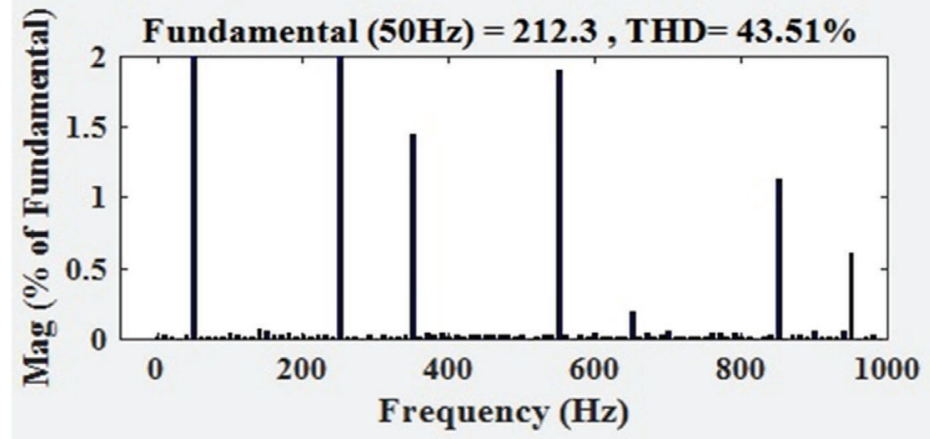

(b)

Figure 9 (a) $66.32 \%$ THD of SPWM at exact modulation, (b) $43.25 \%$ THD of SPWM at over modulation.

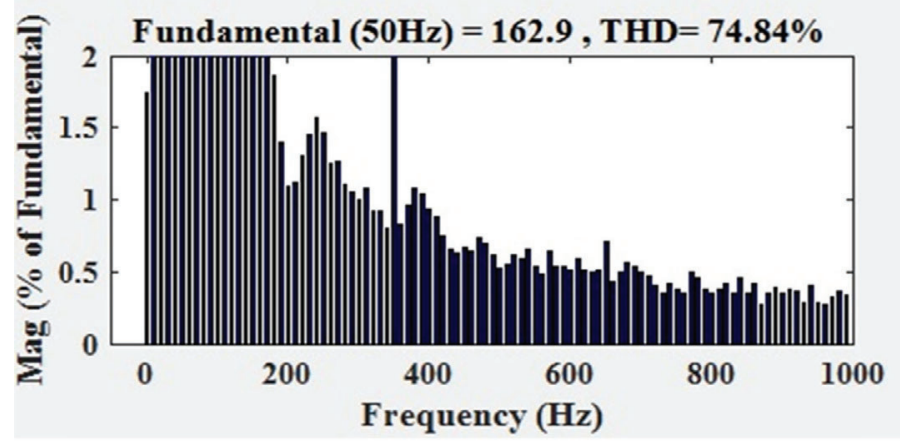

(a)

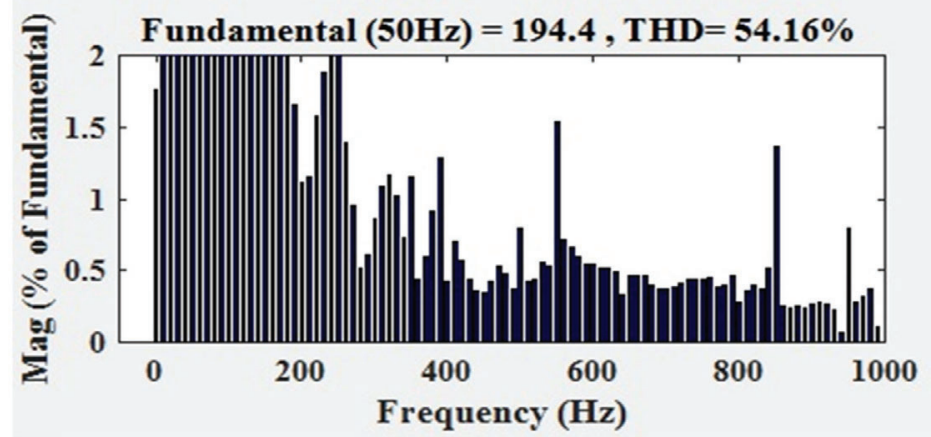

(b)

Figure 10 (a) $75.84 \%$ THD of THIPWM at exact modulation, (b) $54.16 \%$ THD of THIPWM at over modulation. 


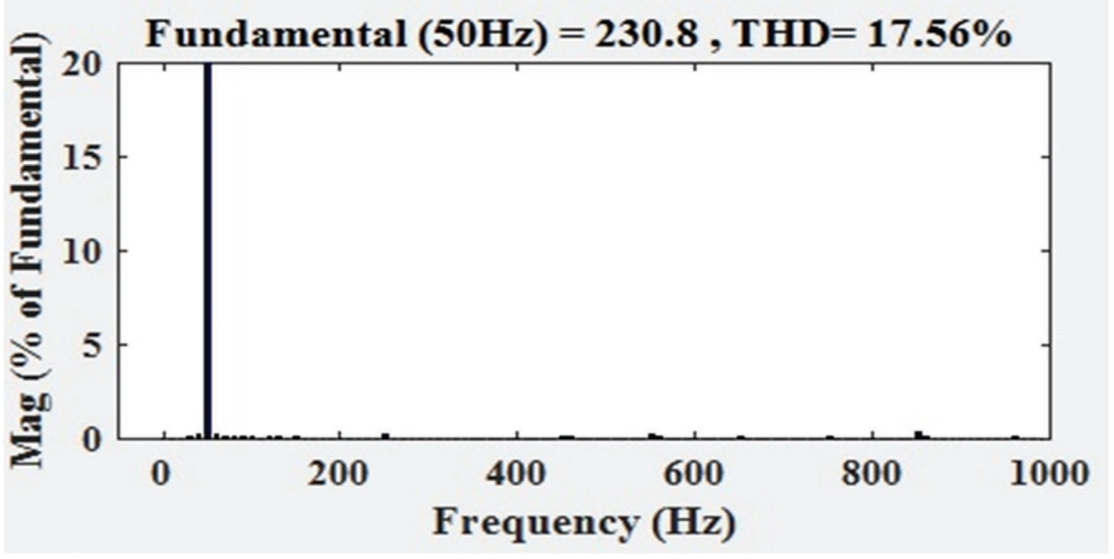

(a)

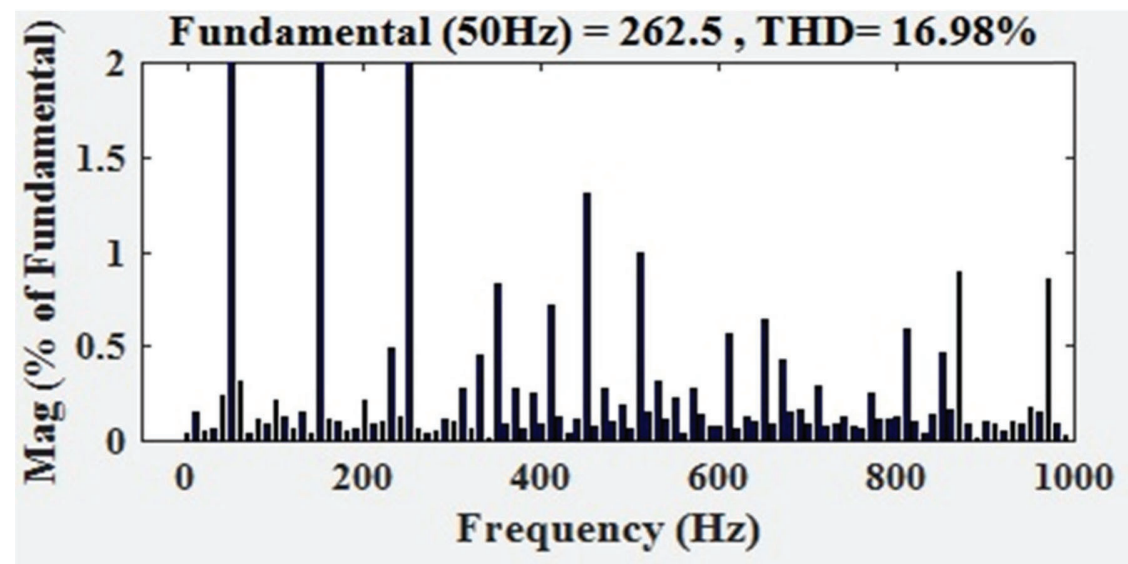

(b)

Figure 11 (a) $17.54 \%$ THD of PDPWM at exact modulation, (b) $16.98 \%$ THD of PDPWM at over modulation.

\subsection{THD Analysis of All Simulation}

The comparison of THD of different techniques based VSI is shown in Table 1 below. Here, we observe that phase disposition pulse width modulation(PDPWM) technique used in multi-level inverter gives better performance and less THD as compared to other methods (SPWM, THIPWM) and also to the papers of reference. 
Table 1

\begin{tabular}{llll}
\hline \multicolumn{4}{c}{$\%$ THD in Load voltage at 230 V input } \\
\hline & SPWM & THIPWM & PDPWM \\
\hline Exact Modulation & 66.32 & 74.84 & 17.56 \\
Over Modulation & 43.51 & 54.16 & 16.98 \\
\hline
\end{tabular}

\section{Discussion and Conclusion}

The THD comparison and analysis of various techniques (SPWM, THIPWM, PDPWM) based voltage source inverter has been carried out through MATLAB simulation. The gate pulse generation circuits are also being discussed for different concluded techniques. As the THD analysis is done above and results are simulated which results, reduction in THD of concluded techniques which may help in reduction in loss and increase in efficiency of system. This system of low THD can be applied in any renewable energy system so that efficiency of that renewable system can be increased. Hence, these voltage source inverters may be used in any application where reduction in system harmonics is required or reduction in losses is required so that we can increase the efficiency of the electrical system. Further, to decrease the value of THD power filter can be used in power circuits. By using such power filter, the final THD of the system can more be reduced to very low value. Unique contribution of this paper is that the 5 switch 7 level voltage source inverter topology is used or compared with other, SPWM and THIPWM technique for better power quality. By this topology the THD is reduced to $16.98 \%$ as compared to $54.16 \%$ or $43.51 \%$ of THIPWM and SPWM techniques respectively.

\section{References}

[1] Rashid, M. H. (2004). Power Electronics Circuits Devices and Applications, 3rd Edn. New Delhi: PHI, 2004.

[2] Bhimbhra, P. S. (2003). Power Electronics, 4th Edn. New Delhi: Khanna Publishers, 2003.

[3] Mohan, N., Undeland, T. M., et al. (2003). Power Electronics Converters, Applications and Design, 3rd Edn. New York, NY: John Wiley \& Sons.

[4] JUNG, J.-W. (2014). Sine PWM Inverter. Columbus, OH: The Ohio State University.

[5] McGrath, B. P., Holmes, D. G. (2002). Multicarrier PWM strategies for multilevel inverters. IEEE Trans. Ind. Electron. 49, 858-867. 
[6] Balamurugan, C. R., Natarajan, S. P., Arumugam, M., and Bensraj, R. (2014). Investigation on three phase five switch multilevel inverter with reduced number of switches. Rev. Ind. Eng. Lett. 1, 67-79.

[7] Gnana Prakash, M., Balamurugan, M., and Umashankar, S. (2014). A new multilevel inverter with reduced number of switches. Int. J. Power Electron. Drive Syst. 5, 63-70.

[8] Prabaharan, N. and Palanisamy, K. (2015). Investigation of single phase reduced switch count asymmetric multilevel inverter using advanced pulse width modulation technique. Int. J. Renew. Ener. Res. 5, 880-890.

[9] Biswamoy P., and Mondal, R. (2014). Overall THD analysis of multicarrier pdpwm based new cascaded multilevel inverter with reduced switch of different levels at different carrier frequency. Int. J. Emerg. Technol. Eng. (IJETE) 1, 148-156.

\section{Biographies}

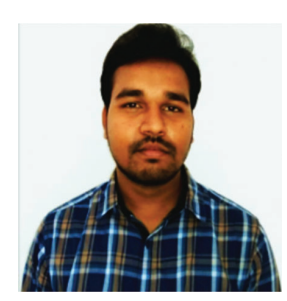

Lokesh Chaturvedi is a final year student of M.Tech at Rajasthan Technical University, Kota. He has done his B.Tech with honors from B. K Birla Institute of Engineering \& Technology, Pilani in 2015. Currently pursuing M.Tech in Department of Electrical Engineering with a specialization of Power Electronics and Electrical Drives. His area of research is in renewable energy specifically in designing of propulsion system architecture for fuel cell vehicles. 


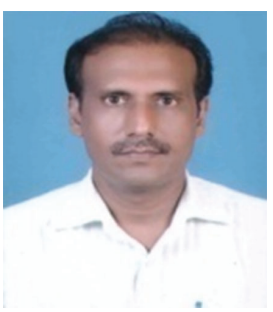

D. K. Yadav received B.E. (Electrical) and M.E. (Power Systems) degree in 1994 and 2007 from University of Rajasthan, Jaipur, India. He completed his Ph.D. degree from IIT Delhi (India). He is Fellow Member of ISLE. His research interest includes design and control of renewable energy systems, hybrid power systems, micro grids, smart grids, power electronic applications in renewable energy systems, hybrid electric vehicles, WECS, solar PV, FC, energy storage devices, integration of RES with utility grid, grid code compliance, distributed generation and impact of increased penetration on power quality and power system.

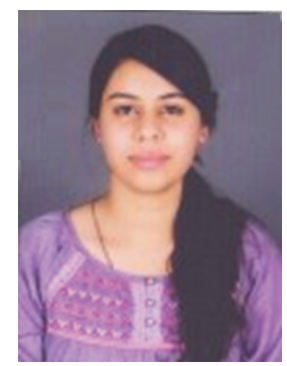

Gargi Pancholi is a final year student of M.Tech at Rajasthan Technical University, Kota. She received the degree of B.Tech with honors in Electrical Engineering from Global Institute of Technology, Jaipur in 2014. She is currently pursuing M.Tech in Department of Electrical Engineering with specialization in Power Electronics and Electrical Drives. Her field of research includes designing of hybrid electric vehicle, energy storage devices and performance of battery in vehicles. 